\title{
Distilled liquid smoke coconut shell attenuates the cytokine profile of macrophages in oral ulcer in experimental model of diabetes mellitus
}

\author{
Meircurius Dwi Condro Surboyo $^{1}$ (D), Diah Savitri Ernawati ${ }^{*}$ (D), Desiana Radithia ${ }^{1}$ (D), Bagus Soebadi ${ }^{1}$ (D), Fatma Yasmin \\ Mahdani $^{1}$ (D), Nurina Febriyanti Ayuningtyas ${ }^{1}$ (D), Fiona Cherrilia Adji ${ }^{2}$, Novia Ambar Larasati ${ }^{2}$ \\ ${ }^{1}$ Department of Oral Medicine. Faculty of Dental Medicine, Universitas Airlangga. Surabaya. Indonesia. \\ ${ }^{2}$ Graduated Student of Doctor Dental Surgery. Faculty of Dental Medicine, Universitas Airlangga, Surabaya, Indonesia.
}

\begin{tabular}{l}
\hline ARTICLE INFO \\
\hline Received on: $12 / 12 / 2020$ \\
Accepted on: $16 / 03 / 2021$ \\
Available online: $05 / 08 / 2021$
\end{tabular}

\section{Key words:}

Distilled liquid smoke

coconut shell, oral

ulcer, diabetes mellitus, proinflammatory cytokines, macrophages.

\begin{abstract}
The effects of distilled liquid smoke coconut shell (DLS-CS) on the macrophages and nuclear factor erythroid2-related factor 2 (Nrf2) and cytokine profiles, that is, tumor necrosis factor $\alpha$ (TNF- $\alpha$ ), interleukin-6 (IL-6), and interleukin-1 $\beta$ (IL-1 $\beta$ ), were analyzed in oral ulcer tissues affected by diabetes mellitus. Wistar rats were injected with alloxan to create diabetes mellitus, and an oral ulcer was made in the inferior labial fornix mucosa. The rats were treated with DLS-CS $20 \mu \mathrm{l} / 20 \mathrm{~g}$ body weight, topically, once a day for 3, 5, and 7 days. The Nrf2, TNF- $\alpha$, IL-6, and IL-1 $\beta$ profiles were analyzed with immunohistochemistry staining and the macrophage count with hematoxylin-eosin staining. The Nrf2 profile was increased after 5 days of treatment and the IL-1 $\beta$ profile was consistently decreased $(p<0.05)$. The IL-6 profile started to decrease after 5 days, while the macrophages increased after 3 and 5 days. No significant difference was found in TNF- $\alpha$ expression. DLS-CS proved effective in decreasing IL- 6 and IL- $1 \beta$ profiles as well as increasing Nrf2 and macrophage migration in oral ulcers with diabetes mellitus.
\end{abstract}

\section{INTRODUCTION}

The prevalence of oral mucosal lesions in diabetes mellitus type 1 and 2 patients is higher than in normal persons, and the most common lesions are ulcerative, such as traumatic and aphthous ulcers, with a prevalence of $24.6 \%$ (GonzálezSerrano et al., 2016; Silva et al., 2015). Oral ulcers can cause pain, disturb nutrition intake and oral hygiene, and increase the risk of infection (Lim et al., 2016). One of the complications found with diabetes mellitus patients' oral ulcers is delayed healing (Selimovic et al., 2010; Suresh et al., 2014). Delayed healing is caused by a prolonged inflammation phase, resulting from the excessive secretion of cytokines of macrophages, such as tumor necrosis factor $\alpha$ (TNF- $\alpha$ ), interleukin-6 (IL-6), and interleukin- $1 \beta$ $(\mathrm{IL}-1 \beta)$. Another factor is a decrease in antioxidant capacity with

\section{"Corresponding Author}

Diah Savitri Ernawati, Department of Oral Medicine.

Faculty of Dental Medicine, Universitas Airlangga. Surabaya. Indonesia. E-mail:diah-s-e@fkg.unair.ac.id the decrease in nuclear factor erythroid-2-related factor 2 (Nrf2). The decrease in Nafr2 increases the migration of macrophages and the level of TNF- $\alpha$, IL-6, and IL- $1 \beta$ (Tian et al., 2018). The oral ulcer, with pain as the chief complaint, is treated with an antiseptic and anti-inflammation drug in the form of a mouthwash (Tripathi and Tripathi, 2015). Sometimes, oral ulcers in diabetes mellitus patients do not respond to medication and an alternative substance is needed (Baltzis et al., 2014; Donath and Shoelson, 2011; Guo and DiPietro, 2010; Panchbhai, 2012; Tsourdi et al., 2013).

Coconut is one of the most common fruits in Indonesia, with consumption reaching 15.5 billion/year. The coconut industry only uses the flesh, and the shells are usually thrown out. Coconut shells are a waste that can be reused because of their contents, such as cellulose, pentosans, lignin, ash, solvents, anhydrous urinate, nitrogen, and water, which have a high potential for antiinflammation and as antioxidants (Surboyo et al., 2012).

Distilled liquid smoke coconut shell (DLS-CS) is a complex liquid compound produced with the pyrolysis of coconut shells at $400^{\circ} \mathrm{C}$ (Budijanto et al., 2008; Wagiman et al, 2014). Coconut shells contain cellulose, hemicellulose, and lignin. The latter substance forms phenolic compounds after going through 
pyrolysis, which has been proven to have analgesic, antiinflammatory, antiseptic, and antioxidant effects (Wagiman et al, 2014). Phenolic compounds are known to be able to decrease secretion and profiles of proinflammation cytokines, that is, TNF- $\alpha$, IL-6, and IL-1 $\beta$ (Ambriz-Pérez et al., 2016; Kang et al., 2017; Lee and Yang, 2012).

TNF- $\alpha$, IL-6, and IL- $1 \beta$ inhibitions are essential for the healing of diabetes mellitus patient's oral ulcers. The cytokine profiles of macrophage (TNF- $\alpha$, IL- 6 , and IL-1 $\beta$ ) inhibition in diabetes mellitus induct transformation of the macrophage phenotype, which is associated with an increased wound growth factor (Mirza et al., 2013). TNF- $\alpha$, IL-6, and IL- $1 \beta$ are also known to decrease collagen synthesis, which is useful in the proliferation phase of wound healing (Adams et al., 1996; Mirza et al., 2013).

DLS-CS is expected to help accelerate the healing of oral ulcers with delayed healing in diabetes mellitus by decreasing the profiles of the proinflammation cytokines of macrophages, such as TNF- $\alpha$, IL- 6 , and IL- $1 \beta$, increasing Nrf2 and promoting macrophage migration. This research was conducted to discover the Nrf2, TNF- $\alpha$, IL- 6 , and IL- $1 \beta$ profiles and macrophage count in oral ulcers with diabetes mellitus as an anti-inflammation indicator for the application of DLS-CS.

\section{MATERIALS AND METHODS}

\section{Distilled liquid smoke coconut shell (DLS-CS) production}

The DLS-CS used in this research is made of (Surboyo et al., 2019a) coconut shells (Cocos nucifera L.) that come from 8- to 10-month-old coconuts. Five kilograms of coconut shells is pyrolyzed at a temperature of $400^{\circ} \mathrm{C}$, with the heating rate of $3.3^{\circ} \mathrm{C}$, for 4 hours and 30 minutes (Surboyo et al., 2019a).

The process produces $51 \%$ distilled liquid smoke, $33.87 \%$ charcoal, and $7.28 \%$ heavy tar. Then, the pyrolysis liquid is deposited twice in 24 hours to precipitate the insoluble components, such as heavy tar. Then, the liquid is filtered using a paper filter and zeolite and distilled at $120^{\circ} \mathrm{C}-150^{\circ} \mathrm{C}$ using a 60-cm-long fractionation column, complete with a condenser, producing an $84 \%$ final yield. The largest components of DLSCS are phenol (36.6\%), furfural $(17.8 \%)$, guaiacol $(14.4 \%)$, 2-methoxy-5-methylphenol (5.2\%), 4-ethyl-2-methoxyphenol (EMP) (3.5\%), and 2-methylphenol (3\%) (Surboyo et al., 2019a).

\section{Diabetic animals model}

The experimental animals used were 36 male Wistar rats (Rattus norvegicus) with the following criteria: 2 months old, 120-160 g, and healthy (active movements and shiny fur). The rats were injected with $150 \mathrm{mg} / \mathrm{kg}$ body weight of alloxan (Alloxan monohydrate A7413, Sigma Aldrich., St. Louis, MO) intraperitoneally to induce diabetes mellitus after being fasted for 12 hours. Diabetes mellitus confirmation was carried out after 72 hours by measuring their fasting glucose level, with a minimum of $200 \mathrm{mg} / \mathrm{dl}$, using GlucoDR (AGM-2100, All Medicus, Korea) (Ajiboye et al., 2018; Ernawati et al., 2019).

This study was carried out in strict accordance with the Guide for the Care and Use of Laboratory Animals of the National Health Research and Development Ethics Standard and Guidelines Council (2017), Minister of Health, Republic of Indonesia. The protocol was approved by the Ethical Clearance of the Health Experiment Committee, Faculty of Dental Medicine,
Airlangga University, Surabaya, with registered number 186/ HRECC.FODM/IV/2019, and all experiments were approved by the Animal Care and Use Committee of Universitas Airlangga.

\section{Oral ulcer and treatment}

Rats confirmed with diabetes were given a $10-\mathrm{mm}$ oral ulcer using a round stainless steel blade in the inferior labial fornix region after anesthesia (ketamine/xylazine cocktail, intraperitoneal, $1 \mathrm{ml}$ ) to reduce pain. Ulceration confirmation was carried out after 24 hours by observing clinical signs, a white-yellowish lesion with a reddish edge (Hitomi et al., 2015; Kiliç et al., 2013).

The rats were then given treatment for the oral ulcer. The treatment was the topical application of distilled water (control), benzydamine hydrochloride (BHCL), and DLS-CS with a dose of $20 \mu \mathrm{l} / 20 \mathrm{~g}$ body weight once a day for 3,5 , and 7 days. The animals were terminated after the topical application of control, BHCL, and DLS-CS in each group, and a specimen of inferior labial fornix was taken to examine the macrophage, IL-6, IL- $1 \beta$, and TNF- $\alpha$ expressions.

\section{Oral ulcer tissue preparation}

After all the groups had been treated for 3, 5, and 7 days, the oral ulcers in the inferior fornix labial region were biopsied. The oral ulcer tissue was fixed using a $10 \%$ formalin buffer solution and then processed in a paraffin block.

\section{Macrophage count}

A histological assessment was carried out by doing hematoxylin-eosin staining and counting macrophages using a microscope with 400x magnification assessed by a single operator in five fields of view.

\section{Nrf2 expression}

Histological assessment was carried out by doing immunohistochemistry staining for Nrf2 expression using a microscope with $400 \times$ magnification with a single operator in five fields of view (Papanicolaou et al., 2012). Nrf2 was used as the primary antibody (1:400; monoclonal; antibody online). The DAB system was used as the secondary antibody (Universal HRP Excell Stain; Biogear; Life Science). Hematoxylin 560 was used as the counterstain (Leica Biosystem).

\section{TNF- $\alpha$, IL-6, and IL-1 $\beta$ expression}

Histological assessment was carried out by doing immunohistochemistry staining and counting macrophage expression of TNF- $\alpha$, IL- 6 , and IL- $1 \beta$ using a microscope with $400 \times$ magnification with a single operator in five fields of view (Kabiraj et al., 2015). TNF- $\alpha$ (1:200; monoclonal; antibody online), IL-6 (1:100; monoclonal; antibody online), and IL-1 $\beta$ (1:200; monoclonal; antibody online) were used as the primary antibodies. The DAB system was used as the secondary antibody (Universal HRP Excell Stain; Biogear; Life Science). Hematoxylin 560 was used as the counterstain (Leica Biosystem).

\section{Data analysis}

Data obtained were analyzed with the one-sample Kolmogorov-Smirnov test for data distribution and the Levene test for data homogeneity. A one-way analysis of variance (ANOVA) 
with the least significant difference (LSD) was carried out for the post-hoc test to assess the difference between macrophage count and Nfr2, IL-6, IL- $1 \beta$, and TNF- $\alpha$ expression between each group, with a significance number of $p<0.05$.

\section{RESULTS AND DISCUSSION}

\section{Diabetic confirmation}

The fasting glucose level and diabetic condition of all the animals were measured. Before injecting alloxan, the animals had a fasting blood glucose $<200 \mathrm{mg} / \mathrm{dl}$. The diabetic condition was confirmed by a fasting blood glucose $>200 \mathrm{mg} / \mathrm{dl}$. After treatment with sterile water, BHCL, and LS-CS, fasting blood glucose was $>200 \mathrm{mg} / \mathrm{dl}$, indicating that the condition still remained (Table 1).

\section{Macrophage count}

The macrophages were counted in the area of the oral ulcer that was formed. The oral ulcer region is characterized by disintegration in the epithelial layer (blue box; Fig. 1A-C). The highest macrophage count was seen in the group treated with DLS-CS. The macrophage count of the DLS-CS group $(9.50 \pm$ $0.58)$, after 3 days of treatment, was significantly higher than that of the BHCL group $(6.00 \pm 1.42)$ and control group $(5.50 \pm 0.58)$ $(p=0.001 ; p=0.000$, resp.) (Fig. 2).

In the 5 days of treatment, the macrophage count of the DLS-CS group $(13.00 \pm 1.83)$ was significantly higher than that of the BHCL group $(8.00 \pm 0.82)$ and control group $(8.75 \pm 0.50)(p$ $=0.000 ; p=0.001$, resp.). In the 7 days of treatment, this did not change $(p=0.089)$ (Fig. 2).

Table 1. Fasting blood glucose during the experiment.

\begin{tabular}{ccccc}
\hline \multirow{2}{*}{ Treatment } & $\begin{array}{c}\text { Days of } \\
\text { treatment }\end{array}$ & \multicolumn{3}{c}{ Fasting blood glucose (mg/dl) } \\
\cline { 2 - 5 } & 3 & $123.00 \pm 8.12$ & $466.75 \pm 46.60$ & $448.25 \pm 40.96$ \\
Before injecting & $\begin{array}{c}\text { Diabetic } \\
\text { condition }\end{array}$ & Termination \\
\hline \multirow{2}{*}{ Control } & 5 & $114.25 \pm 10.81$ & $376.50 \pm 66.31$ & $331.75 \pm 50.60$ \\
& 7 & $109.50 \pm 12.48$ & $329.00 \pm 81.63$ & $451.50 \pm 68.47$ \\
& 3 & $107.00 \pm 14.72$ & $498.75 \pm 46.92$ & $408.00 \pm 47.25$ \\
BHCL & 5 & $109.00 \pm 9.69$ & $315.25 \pm 64.05$ & $376.00 \pm 51.19$ \\
& 7 & $102.75 \pm 26.25$ & $382.50 \pm 73.57$ & $335.50 \pm 68.92$ \\
& 3 & $108.50 \pm 5.45$ & $388.25 \pm 77.51$ & $470.50 \pm 74.25$ \\
DLS-CS & 5 & $110.50 \pm 7.59$ & $485.50 \pm 75.77$ & $364.00 \pm 81.64$ \\
& 7 & $109.50 \pm 5.80$ & $494.75 \pm 69.44$ & $402.00 \pm 89.05$ \\
\hline
\end{tabular}

In the diabetes mellitus condition, there is a delay in macrophage recruitment, causing the accumulation of macrophages in inflamed tissue and an increase in proinflammatory cytokine secretion (Yan et al., 2018). Treatment with DLS-CS showed higher macrophage count and increased macrophage recruitment. The previous study confirmed that cellular response also increased after treatment, especially in the recruitment of neutrophils (Ernawati et al., 2020).

\section{Nrf2 expression}

Nrf2 expression was analyzed in the macrophages (Fig. $3)$. The Nrf2 profile increased after 5 days of treatment in the DLSCS group, unlike the control group $(p=0.003)$. In the 7 days of treatment, the Nrf2 profile also increased more in the DLS-CS group $(68.75+1.50)$ than the control groups $(56.25+4.27)(p=$ $0.000)$. The increased Nrf2 profile in treatment with DLS-CS is the integral mechanism aimed at counterbalancing nuclear factor kappa B (NF- $\kappa \mathrm{B}$ ) activation (Ahmed et al., 2017). DLS-CS has a role in stimulating NF- $\kappa \mathrm{B}$ activation in diabetes. NF- $\kappa \mathrm{B}$ activation leads to the release of proinflammatory cytokines, such as TNF- $\alpha$, IL-6, and IL-1 $\beta$ (Surboyo et al., 2019a). The increased Nrf2 profile leads to an increase in anti-inflammatory cytokine secretion and the growth factor. In other researches, treatment with DLS-CS was able to stimulate the fibroblast and secretion of the fibroblast and vascular endothelial growth factors (Ayuningtyas et al., 2020).

\section{TNF- $\alpha$, IL-6, and IL-1 $\beta$ expression}

TNF- $\alpha$, IL- 6 , and IL- $1 \beta$ expression was analyzed in the macrophages (Figs. 4-6, resp.). The highest cytokine profiles were found in the control group and the lowest in the DLS-CS group. The BHCL and DLS-CS groups showed a decrease in TNF- $\alpha$, IL-6, and IL- $1 \beta$ expression, while the control group showed an increase in TNF- $\alpha$, IL- 6 , and IL- $1 \beta$ expression.

After 3 days of treatment, the IL- $1 \beta$ profile of the DLSCS group $(9.25 \pm 0.96)$ was significantly lower than that of the BHCL (11.00 \pm 0.82$)$ and control groups $(11.75 \pm 0.96)(p=$ $0.024 ; p=0.004$, resp.) (Fig. 7A).

After 5 days of treatment, the IL- 6 profile of the DLSCS group $(7.25 \pm 0.50)$ was significantly lower than that of the BHCL (9.25 \pm 0.96$)$ and control groups $(11.5 \pm 1.29)(p=0.017$; $p=0.000$, resp.). A similar pattern was found in the IL- $1 \beta$ profile, where the DLS-CS group $(8.25 \pm 0.96)$ showed a significantly lower profile compared to the other two groups (BHCL: $10.00 \pm$ 0.82; control: $12.50 \pm 1.30)(p=0.041 ; p=0.000$, resp.) (Fig. 7B).

After 7 days of treatment, the IL- 6 profile of the DLSCS group $(5.50 \pm 1.29)$ was significantly lower than that of the
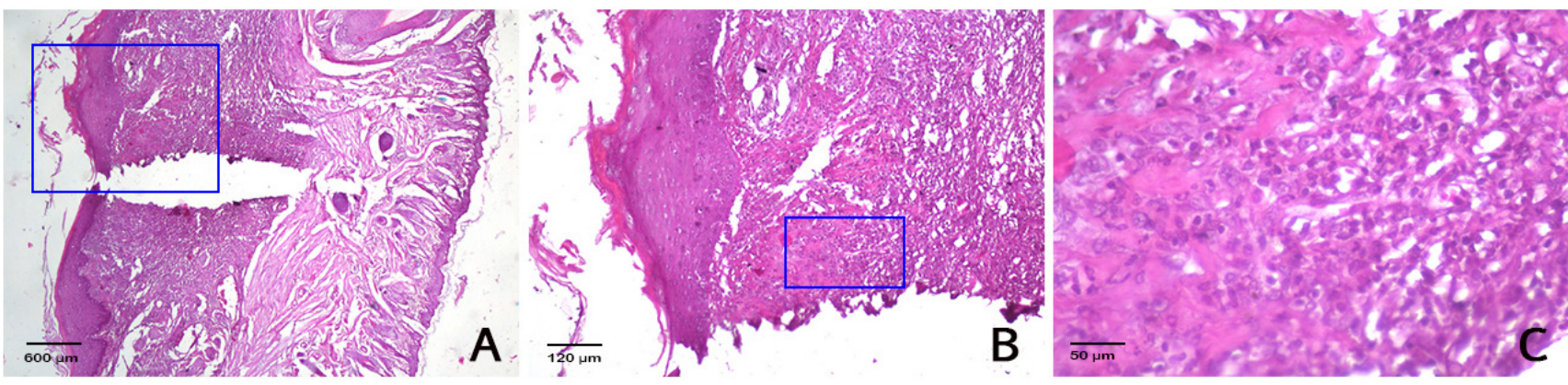

Figure 1. (A) The oral ulcer area (magnification: 40×). (B) The area of analysis (magnification $100 \times$ ). (C) The macrophage count in the oral ulcer area (magnification $400 \times$ ). 

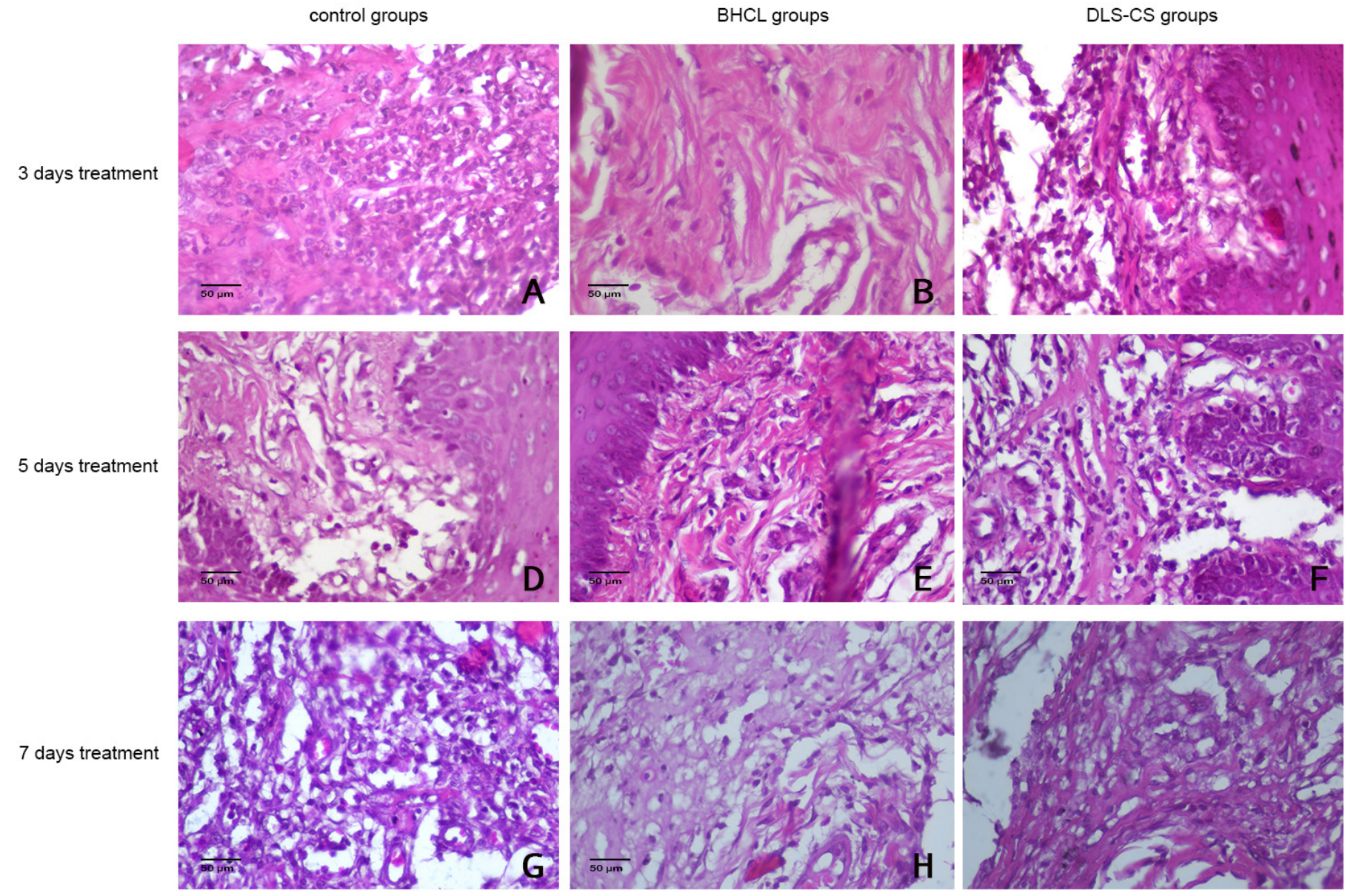

Figure 2. The histopathology of the oral ulcer area for macrophage number analysis (magnification $400 \times$ ).

$\operatorname{BHCL}(8.50 \pm 0.58)$ and control groups $(12.25 \pm 0.96)(p=0.002$; $p=0.000$, resp.). A similar pattern was found in the IL- $1 \beta$ profile, where the DLS-CS group's $(6.75 \pm 0.96)$ profile was significantly lower than those of the other two groups (BHCL: $9.50 \pm 0.58$; control: $14.00 \pm 0.82)(p=0.001 ; p=0.000$, resp.) (Fig. 7C).

The TNF- $\alpha$ profile showed no significant difference in the DLS-CS groups, compared to the BHCL and control group, after three $(p=0.09)$, five $(p=0.577)$, and seven $(p=0.256)$ days of treatment. TNF- $\alpha$, IL- 6 , and IL- $1 \beta$ are proinflammatory cytokines with essential roles in the wound healing process in diabetes mellitus. Inhibition of excessive IL- $1 \beta$ in diabetes mellitus could promote oral ulcer healing by switching the phenotype of macrophages from proinflammatory to healing-associated and increasing wound growth factor production, while IL-6 is directly connected to the pathogenesis of diabetes mellitus (Mirza et al., 2013; Saiki et al., 2018). IL-1 $\beta$ is also associated with diabetes mellitus pathology. Accelerated healing of oral ulcers in diabetes mellitus patients will increase their quality of life by eliminating pain, thus improving nutrition intake and oral hygiene. Oral ulcer healing also decreases the risk of secondary infection caused by delayed healing (Lim et al., 2016).

The group treated with DLS-CS showed lower IL-6 and IL- $1 \beta$ profiles than the other groups. DLS-CS was able to decrease the IL- 6 and IL- $1 \beta$ profiles consistently and progressively during treatment as well as increase macrophage migration to the inflammation sites. The mechanism that may have caused this process might be the phenolic compounds contained in DLS-CS. Phenolic compounds regulate the activity of transcription factors such as NF- $\kappa$ B (Surboyo et al., 2019a) and Nrf2, inhibiting the activity of the cyclooxygenase enzyme and the profiles of another inflammation mediator. DLS-CS proved to reduce NF- $\kappa$ B activity in the research conducted by Surboyo et al. (2019a). The research also states that the topical application of DLS-CS shows a lower TNF- $\alpha$ profile. Lower TNF- $\alpha$ profile synergies with lower IL- 6 and IL- $1 \beta$ profiles are consequences of lower NF- $\kappa$ B activity due to treatment with DLS-CS (Surboyo et al., 2019a, 2020). The results of this research also support that DLS-CS is able to increase or stimulate $\mathrm{Nfr} 2$ as compensation for the suppression of $\mathrm{NF}-\kappa \mathrm{B}$.

Phenolic compounds, such as EMP and guaiacol (2-methoxyphenol), also have antioxidative properties, preventing oxidative stress and decreasing proinflammatory cytokine secretion, such as TNF- $\alpha$, IL-6, and IL- $1 \beta$. EMP is a guaiacol compound that possesses strong antioxidant properties, binding $\mathrm{ONOO}^{-}$and resulting in the inhibition of NF- $\kappa \mathrm{B}$ activation and decrease of proinflammatory cytokine secretion. Guaiacol has two functional groups: a hydroxyl $(-\mathrm{OH})$ and a methoxy group ($\mathrm{OCH}_{3}$ ), which able to bind free radicals due to their high ionization potential to form hydrogen bonds and inhibit superoxide radicals by donating hydrogen atoms to $-\mathrm{OH}$, forming $\mathrm{H}_{2} \mathrm{O}$. Prevention of oxidative stress could decrease NO synthase activity in 


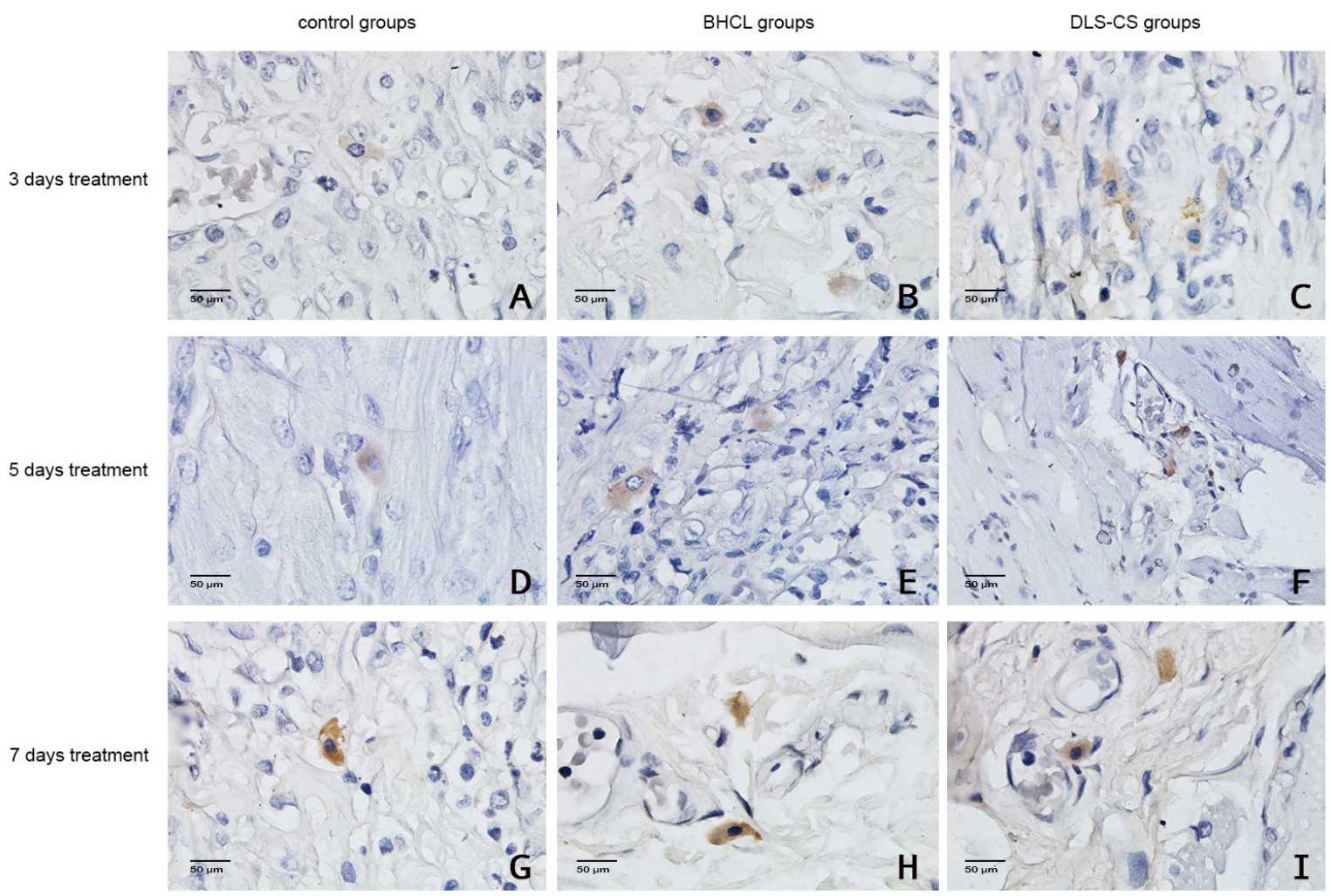

Figure 3. Nrf2 expression in the oral ulcer area (magnification: 400×).

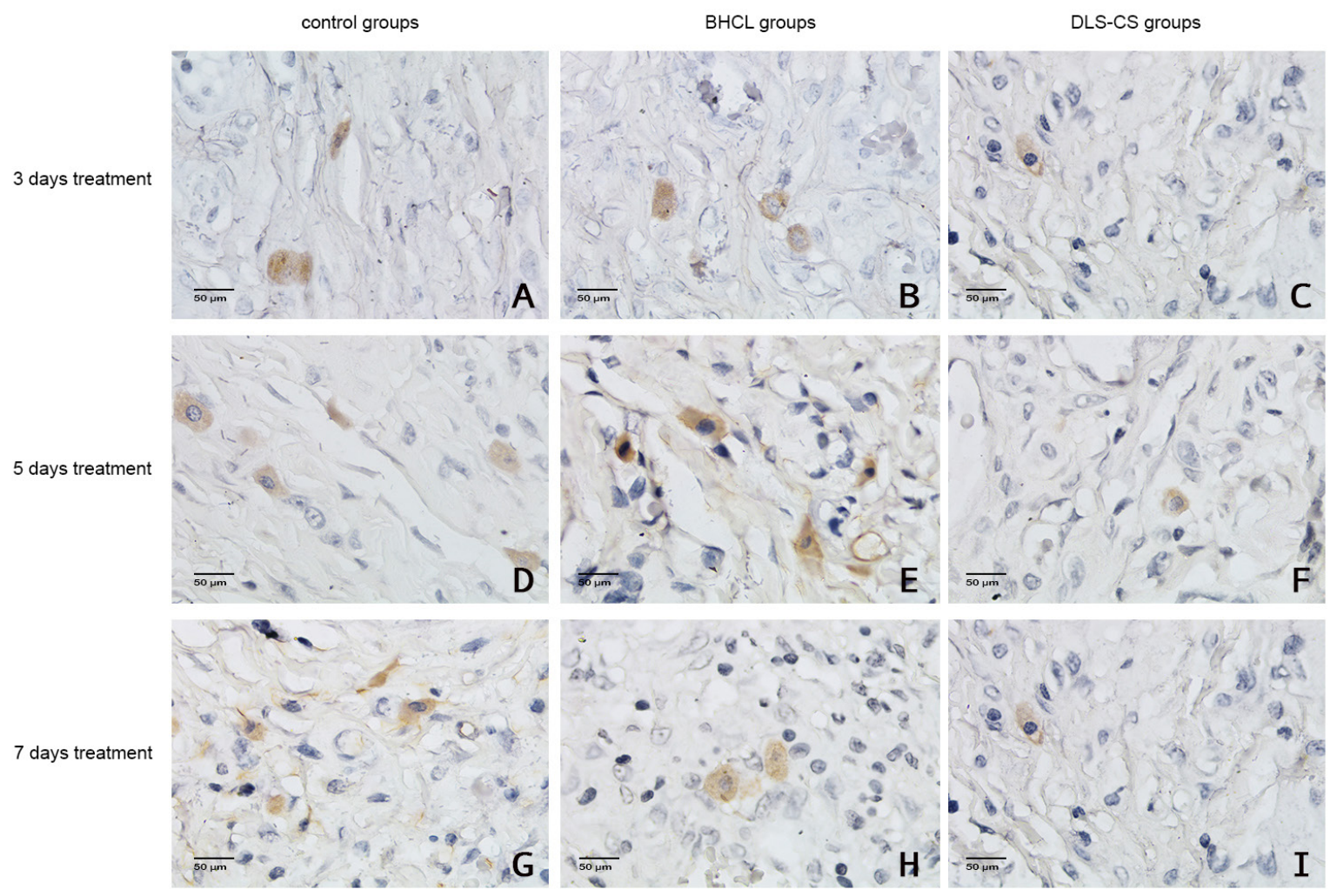

Figure 4. TNF- $\alpha$ expression in the oral ulcer area (magnification: 400×). 


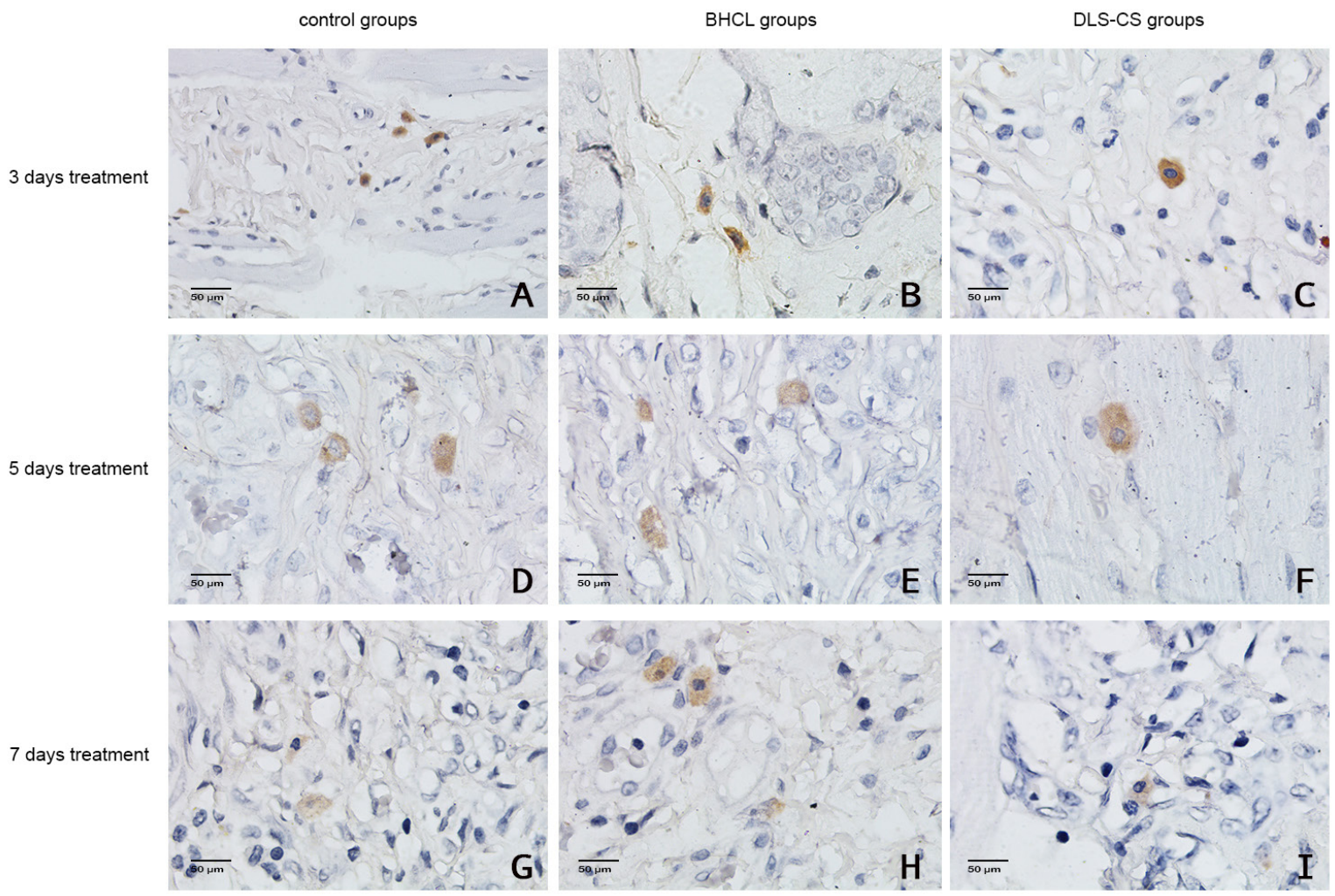

Figure 5. IL-6 expression in the oral ulcer area (magnification: 400×).

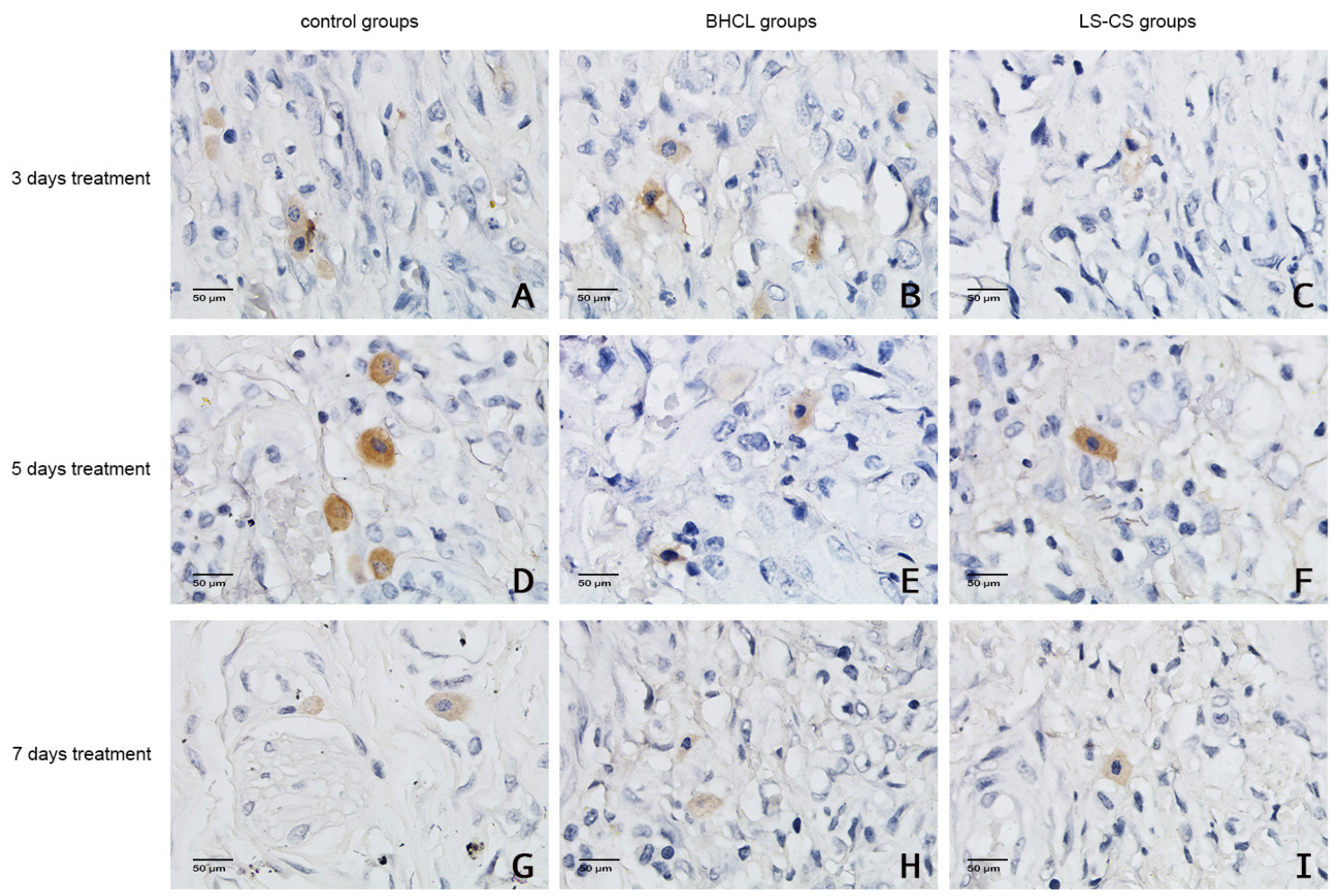

Figure 6. IL-1 $\beta$ expression in the oral ulcer area (magnification: $400 \times$ ). 


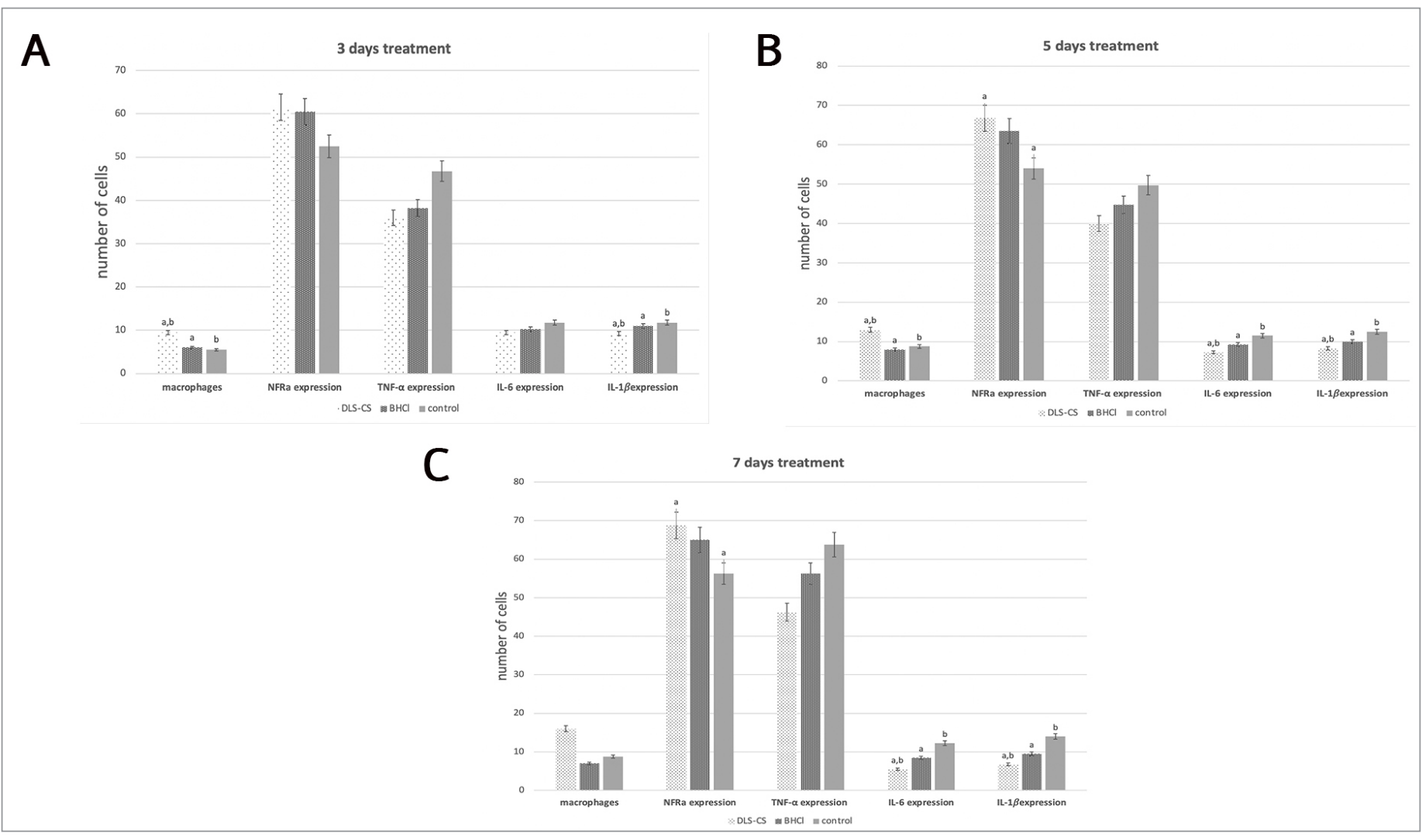

Figure 7. The macrophages number, Nfr2, IL-6, IL-1 $\beta$, and TNF- $\alpha$ expression. (A) Three days of treatment; (B) 5 days of treatment; and (C) 7 days of treatment. Each piece of data is presented as the mean \pm SD. The character on top of each bar is significantly different, with other groups using the ANOVA and LSD tests $(p<0.05)$.

macrophages and reduce $\mathrm{NF}-\kappa \mathrm{B}$ activity and proinflammatory cytokine secretion. Lower profiles of TNF- $\alpha$, IL-6, and IL- $1 \beta$ could increase the proliferation of fibroblasts and collagen synthesis and promote oral ulcer healing (Surboyo et al., 2019; Suryavanshi and Kulkarni, 2017; Tarawan et al., 2017; Surboyo et al., 2017; Surboyo et al., 2019b; Suryavanshi and Kulkarni, 2017).

Higher macrophage count was observed in groups treated with DLS-CS, but cytokine assessment showed a lower profile of proinflammatory cytokines. This indicates that DLS-CS promotes macrophage migration to inflammation sites but suppresses their activity to secrete proinflammatory cytokines, such as IL-6, IL-1 $\beta$, and TNF- $\alpha$. The TNF- $\alpha$ profile in this research did not show any difference between treatment with DLS-CS, BHCL, and control. This might happen because TNF- $\alpha$ is not the only proinflammatory cytokine secreted during the inflammation phase; there are a couple of proinflammatory cytokines that are secreted at the same time as TNF- $\alpha$, such as IL-6 and IL-1 $\beta$ (Turner et al., 2014).

DLS-CS has proven effective in decreasing IL-6 and IL$1 \beta$ profiles and increasing Nrf2 profiles and macrophage migration. IL-6 and IL-1 $\beta$ reduction might involve phenolic compounds contained by DLS-CS, which are able to regulate Nfr2 and NF-$\mathrm{B}$ activity and prevent oxidative stress and are proven to promote the clinical healing of oral ulcers.

\section{FUNDING}

This work was supported by Kementerian Riset Teknologi dan Pendidikan Tinggi Republik Indonesia in 2019 with grant number 6/E/KTP/2019.

\section{AUTHOR CONTRIBUTIONS}

All authors made substantial contributions to conception and design, acquisition of data, or analysis and interpretation of data; took part in drafting the article or revising it critically for important intellectual content; agreed to submit to the current journal; gave final approval of the version to be published; and agree to be accountable for all aspects of the work. All the authors are eligible to be an author as per the international committee of medical journal editors (ICMJE) requirements/guidelines.

\section{CONFLICTS OF INTEREST}

The authors report no financial or any other conflicts of interest in this work.

\section{ETHICAL APPROVALS}

The protocol was approved by the Ethical Clearance of the Health Experiment Committee, Faculty of Dental Medicine, Airlangga University, Surabaya, with registered number 186/ HRECC.FODM/IV/2019, and all experiments were approved by the Animal Care and Use Committee of Universitas Airlangga.

\section{PUBLISHER'S NOTE}

This journal remains neutral with regard to jurisdictional claims in published institutional affiliation.

\section{REFERENCES}

Adams J, Willey A, Yager D, Diegelmann RF, Graham MF. Interleukin 1 beta down-regulates collagen and augments collagenase 
expression in human intestinal smooth muscle cells. Gastroenterology, 1996; 110(2):344-50.

Ahmed SMU, Lin L, Akhileshwar N, Xiu JW, Xiuwen T. Nrf2 signaling pathway: Pivotal roles in inflammation. Biochim Biophys Acta Mol Basis Dis, 2017; 1863(2):585-97.

Ajiboye BO, Hussein OB, Oloyede, Musa O. Antihyperglycemic and antidyslipidemic activity of musa paradisiaca-based diet in alloxaninduced diabetic rats. Food Sci Nutr, 2018; 6(1):137-45.

Ambriz-Pérez DL, Nayely LL, Erick PG, Heredia JB. Phenolic compounds: natural alternative in inflammation treatment. A review. Cogent Food Agric, 2016; 2(1):1-14.

Ayuningtyas NF, Surboyo MDC, Ernawati DS, Parmadiati AE. The role of liquid smoke coconut shell in the proliferation phase of an oral traumatic ulcer. J Pharm Pharmacogn Res, 2020; 8(6):549-57.

Baltzis D, Eleftheriadou I, Veves A. Pathogenesis and treatment of impaired wound healing in diabetes mellitus: new insights. Adv Ther, 2014; 31(8):817-36.

Budijanto S, Hasbullah R, Prabawati S, Setyadjit, Sukarno, Zuraida I. Identification and safety test on liquid smoke made from coconut shell for food product. Indones J Agric Postharvest Res, 2008; 5(1):32-40.

Donath MY, Shoelson SE. Type 2 diabetes as an inflammatory disease. Nat Rev Immunol, 2011; 11(2):98-107.

Ernawati DS, Surboyo MDC, Ayuningtyas NF, Nagoro AAB. Role of inflammatory cell responses in stimulating fibroblasts in diabetic oral ulcer after treatment with liquid smoke of coconut endocarp: a histological assessment. Eur J Dent, 2020: 15(1):71-6.

González-Serrano J, Serrano J, López-Pintor RM, Paredes VM, Casañas E, Hernández G. Prevalence of oral mucosal disorders in diabetes mellitus patients compared with a control group. J Diabetes Res, 2016; 2016:5048967.

Guo S, DiPietro LA. Factors affecting wound healing. J Dent Res, 2010; 89(3):219-29.

Hitomi S, Ono K, Miyano K, Ota Y, Uezono Y, Matoba M, Kuramitsu S, Yamaguchi K, Matsuo K, Seta Y, Harano N, Inenaga K. Novel methods of applying direct chemical and mechanical stimulation to the oral mucosa for traditional behavioral pain assays in conscious rats. J Neurosci Methods, 2015; 239:162-9.

Kabiraj A, Gupta J, Khaitan T, Bhattacharya P. Principle and techniques of immunohistochemistry - a review. Int J Biol Med Res, 2015; 6(3):5204-10.

Kang X, Qiu J, Li Q, Bell KA, Du Y, Jung DW, Lee JY, Hao J, Jiang J. Cyclooxygenase-2 contributes to oxidopamine-mediated neuronal inflammation and injury via the prostaglandin E2 receptor EP2 subtype. Sci Rep, 2017; 7(1):1-14.

Kiliç Ç, Peker EGG, Acartürk F, Kiliçaslan SMS, Cevher SC. Investigation of the effects of local glutathione and chitosan administration on incisional oral mucosal wound healing in rabbits. Colloids Surf B Biointerfaces, 2013; 112:499-507.

Lee IT, Yang CM. Role of nadph oxidase/ros in pro-inflammatory mediators-induced airway and pulmonary diseases. Biochem Pharmacol, 2012; 84(5):581-90.

Lim YS, Kwon SK, Park JH, Cho CG, Park SW, Kim WK. Enhanced mucosal healing with curcumin in animal oral ulcer model. Laryngoscope, 2016; 126(2):E68-73.

Mirza RE, Fang MM, Ennis WJ, Kohl TJ. Blocking interleukin$1 \beta$ induces a healing-associated wound macrophage phenotype and improves healing in type 2 diabetes. Diabetes, 2013; 62(7):2579-87.

Panchbhai AS. Correlation of salivary glucose level with blood glucose level in diabetes mellitus. J Oral Maxillofac Res, 2012; 3(3):1-7.

Papanicolaou P, Chrysomali E, Stylogianni E, Donta C, Vlachodimitropoulos D. Increased TNF-alfa, IL-6 and decreased IL-1beta immunohistochemical expression by the stromal spindle-shaped cells in the central giant cell granuloma of the jaws. Med Oral Patol Oral Cir Bucal 2012; 17(1):e56-62.

Saiki P, Nakajima Y, Van Griensven LJLD, Miyazaki K. Realtime monitoring of IL-6 and IL-10 reporter expression for anti-inflammation activity in live raw 264.7 cells. Biochem Biophys Res Commun, 2018; 505:885-90.

Selimovic A, Selimovic Y, Selimovic D. The mechanism of protracted wound healing on ral mucosa in diabetes. Review. Bosn J Basic Med Sci, 2010; 10(3):186-91.

Silva MFA, Barbosa KGN, Pereira JV, Bento PM, Godoy GP, Gomes DQC. Prevalence of oral mucosal lesions among patients with diabetes mellitus types 1 and 2. An Bras Dermatol, 2015; 90(1):49-53.

Surboyo MDC, Arundina I, Rahayu RP. Increase of collagen in diabetes-related traumatic ulcers after the application of liquid smoke coconut shell. Dent J, 2017; 71(32):71-5.

Surboyo MDC, Arundina I, Rahayu RP, Mansur D, Bramantoro T. Potential of distilled liquid smoke derived from coconut (cocos nucifera 1) shell for traumatic ulcer healing in diabetic rats. Eur J Dent, 2019a; 13(02):271-9

Surboyo MDC, Ernawati DS, Arundina I, Rahayu RP. Oral ulcer healing after treatment with distilled liquid smoke of coconut shell on diabetic rats. J Krishna Inst Med Sci Univ, 2019b; 8(2):70-9.

Surboyo MDC, Mahdani FY, Ernawati DS, Sarasati A, Rezkita F. The macrophage responses during diabetic oral ulcer healing by liquid coconut shell smoke: an immunohistochemical analysis. Eur J Dent, 2020; 14(03):410-4

Surboyo MDC, Tantiana, Arundina I. Analgesic effect of coconut shell (cocos nucifera L) liquid smoke on mice. Dent J, 2012; 45(3):156-60.

Suresh DH, Suryanarayan S, Sarvajnamurthy S, Puvvadi S. Treatment of a non-healing diabetic foot ulcer with platelet-rich plasma. J Cutan Aesthet Surg, 2014; 7(4):229-31.

Suryavanshi SV, Kulkarni YA. NF- $\kappa \beta$ : a potential target in the management of vascular complications of diabetes. Front Pharmacol, 2017; 8(798): 1-12.

Tarawan VM, Mantilidewi KI, Dhini IM, Radhiyanti PT, Sutedja E. Coconut shell liquid smoke promotes burn wound healing. J Evid Based Complementary Altern Med, 2017; 22(3):436-40.

Tian X, Wang F, Luo Y, Ma S, Zhang N, Sun Y, You C, Tang G, Li S, Gong Y, Xie C. Protective role of nuclear factor-erythroid 2-related factor 2 against radiation-induced lung injury and inflammation. Front Oncol, 2018; 8:1-11.

Tripathi R, Tripathi K. Management of non-healing oral ulcer in diabetic patient using topical application of epidermal growth factor: a case report. Sch Acad J Biosci, 2015; 3(8):640-3.

Tsourdi E, Barthel A, Rietzsch H, Reichel A, Bornstein SR. Current aspects in the pathophysiology and treatment of chronic wounds in diabetes mellitus. Biomed Res Int, 2013: 2013:1-6.

Turner MD, Nedjai B, Hurst T, Pennington DJ. Cytokines and chemokines: at the crossroads of cell signalling and inflammatory disease. Biochim Biophys Acta, 2014; 1843(11):2563-82.

Wagiman FX, Ardiansyah A, Witjaksono. Activity of coconutshell liquid-smoke as an insecticide on the rice brown planthopper (Nilaparvata lugens). J Agric Biol Sci, 2014; 9(9):293-6.

Yan J, Tie G, Wang S, Tutto A, Demarco N, Khair L, Fazzio TG, Messina LM. Diabetes impairs wound healing by dnmt1-dependent dysregulation of hematopoietic stem cells differentiation towards macrophages. Nat Commun, 2018; 9(33):1-13.

How to cite this article:

MDC Surboyo, Ernawati DS, Radithia D, Soebadi B, Mahdani FY, Ayuningtyas NF, Adji FC, Larasati NA. Distilled liquid smoke coconut shell attenuates the cytokines profile of macrophages in oral ulcer in experimental model of diabetes mellitus. J Appl Pharm Sci, 2021; 11(08):062-069. 